\title{
Learning to evolve
}

\section{A fresh look at whether learning alters the course of natural selection.}

\section{Evolution and Learning: The Baldwin Effect Reconsidered edited by Bruce H. Weber \& \\ David J. Depew \\ MIT Press: 2003.352 pp. $\$ 45, £ 29.50$ \\ Kevin N. Laland}

At the start of the twentieth century, James Mark Baldwin, professor of psychology at Johns Hopkins University and former president of the American Psychological Association, was one of the United States' leading developmental psychologists. Tragically, he was forced to resign his posts after being arrested in a brothel, and his substantial contributions to psychology were written out of the history books.

This salacious snippet would probably have been long forgotten had Baldwin not left the conceptual legacy of a mechanism purporting to allow 'mind' to guide evolution. The idea is that organisms could survive ecological challenges by virtue of their acquired knowledge and skills, frequently learned from others, and that this would then channel natural selection to favour unlearned versions of the same adaptive behaviour, perhaps because such variants more reliably facilitate survival. Conwy Lloyd Morgan and Henry F. Osborn published identical conjectures at about the same time, but Baldwin asserted his priority, and the mechanism is now known as the Baldwin effect.

Baldwin received heavyweight backing from Julian Huxley, Jean Piaget and Conrad Waddington among others, but few evolutionary biologists have allotted much thought or credence to the notion, and leading figures such as George Simpson and Ernst Mayr were hostile. But the Baldwin effect has recently re-emerged, receiving theoretical support, being endorsed by John Maynard Smith and cropping up in theories of the evolution of language and mind.

In this collection of thought-provoking essays on learning and evolution, editors Bruce Weber and David Depew set out to reconsider the Baldwin effect in the light of these developments, exploring whether it has anything to add to contemporary debates about evolution. The 14 contributors are mainly philosophers, psychologists or developmental biologists; strikingly, none are evolutionary biologists.

Although not all are 'Baldwin boosters', most concur that there is something missing from modern evolutionary biology. For instance, Terrence Deacon and Daniel Dennett feel the need for tools in addition to natural selection to describe their theories

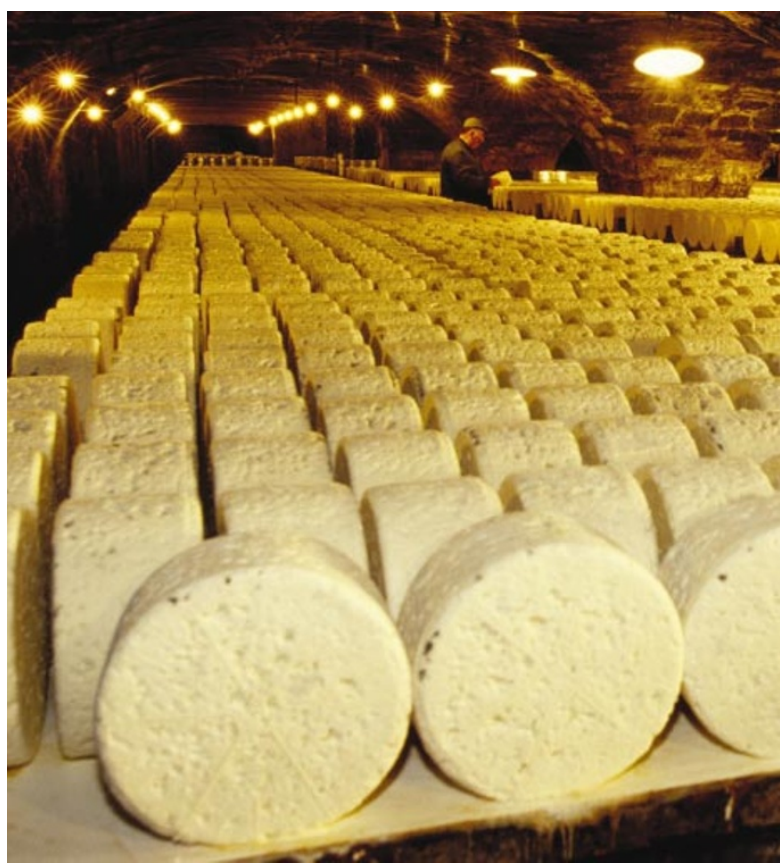

Cheese spread: the emergence of dairy farming may have created the selection pressures that favoured genes for lactose absorption. that organisms shape the environments in which they live - and ecological (extragenetic) inheritance. The only sense in which the Baldwin effect can be regarded as a new factor in evolution is that traits not fully specified by naturally selected genes modify selection pressures acting back on the organism. There is no reason why such traits should be restricted to learned behaviour, because few traits are genetically determined, nor why the modified selection should be restricted to that favouring genes for the trait. All living creatures, through their metabolism, activities and choices, partly create and partly destroy their own niches.

I suspect that evoluof language and brain evolution, and evoke the Baldwin effect as the best available mechanism. Celia Moore, Susan Oyama and Paul Griffiths would like to see a broadening of the notion of inheritance to include epigenetic and social factors. Highlights of the collection include Deacon's imaginative account of the coevolution of language and brain, a delightful essay by Moore depicting the complexities of behavioural development with vivid examples, and a characteristically astute deconstruction of the Baldwin effect by Peter Godfrey-Smith. But the contributor who puts his finger on the problem is Griffiths.

Baldwin was a prescient character who anticipated much of the causal logic behind gene-culture coevolutionary theory and developmental-systems theory. And he was right. For example, around the world, both the proportion of the adult population able to consume dairy products without becoming sick and the frequency of genes for lactose absorption covary strongly with a history of dairy farming. Recent comparative analyses reveal that dairy farming emerged before the spread of genes for lactose absorption and almost certainly created the selection pressures that favoured them, not the other way around.

Yet, as Griffiths argues, the Baldwin effect distracts attention from the more fundamental processes of niche construction - the idea tionary biologists feel that they can ignore Baldwin because the early developmental sequestering of germline from somatic cells means that developmental processes, including learning, do not directly affect genetic inheritance. Yet by modifying selection pressures that act back on the organism, niche construction creates an indirect causal pathway. The widespread assumption that niche construction is a product of evolution but not a process in its own right is tantamount to the assumption that development is fully determined by naturally selected genes.

A minor gripe about the book is that it is sometimes repetitive: after the first couple of chapters the reader no longer needs to be told what the Baldwin effect is. Furthermore, some relevant empirical and theoretical findings are ignored, including much of the recent work on the evolution of plasticity and reaction norms, and the best theoretical analysis of the Baldwin effect (L. W. Ancel, J. Theor. Biol. 196, 197-209; 1999). Yet these deficiencies detract little from the exercise. Evolution and Learning is a readable and challenging volume, and I would recommend it strongly to people who enjoy thinking hard about evolution.

Kevin N. Laland is at the School of Biology, Bute Medical Building, University of St Andrews,

St Andrews, Fife KY16 9TS, UK. He is a co-author of Niche Construction: The Neglected Process in Evolution (Princeton University Press, 2003). 